\title{
CALORIMETRIC DETERMINATIONS OF THERMAL PROP. ERTIES OF METHYL ALCOHOL, ETHYL ALCOHOL, AND BENZENE
}

\author{
By E. F. Fiock, D. C. Ginnings, and W. B. Holton
}

AESTRACT

The method and calorimetric equipment previously used in the determination of thermal properties of saturated water and steam were applied, without essential modification, in an investigation of corresponding properties of methyl alcohol, ethyl alcohol, and benzene. Precautions were taken to obtain these liquids in a very pure state. Determinations were made in the range from $40^{\circ}$ to $110^{\circ} \mathrm{C}$., yielding values of latent heats of vaporization and changes in heat content. Empirical equations fitted to these properties aid in the interpolation, extropolation, and application of the data. An estimate is made of the precision of the final results. A skeleton table of the more commonly used thermal properties of the saturated liquids and vapors has been prepared. Comparisons with the values of previous investigators are included.

\section{CONTENTS}

I. Introduction

II. Method, apparatus, and procedure. 882

III. Notation

IV. Preparation and physical properties of compounds......... 885

1. Methyl alcohol_._. 885

2. Ethyl alcohol

3. Benzene $\ldots \ldots$

V. Results of measurements.

VI. Discussion of accuracy

VII. Comparison with previous work

1. Heat capacity

2. Latent heat. VIII. Summary

\section{INTRODUCTION}

The calorimetric equipment which was designed and used at the National Bureau of Standards ${ }^{1}$ for the measurement of thermal properties of saturated water and steam became available for a limited survey of similar properties of other liquids upon completion of the initial steam program. Reliable thermal data on methyl alcohol, ethyl alcohol, and benzene were needed to supplement calorimetric measurements on heats of combustion which are now in progress at this bureau. On account of the physical and chemical properties of these liquids, the apparatus could be used without essential modification. They can be obtained in comparatively pure form, and their purity can be estimated by rather simple physical measurements. 


\section{METHOD, APPARATUS, AND PROCEDURE}

Each of the three organic liquids already mentioned was subjected to two distinct calorimetric processes. The first of these consisted in heating a known mass of the fluid from one saturation temperature to another, observing the total energy added and the temperature rise. Such measurements yield essentially the change in heat content or enthalpy of the calorimeter and its contents over the observed temperature interval. The second process consisted in removing saturated vapor from the calorimeter at practically constant temperature. These measurements yield essentially the value of the latent heat of vaporization at the temperature of the experiments.

To obtain values of heat content and of latent heat from the measurements as they were performed, a correction is necessary to take into account the change in the ratio of the masses of liquid and vapor in the calorimeter from the beginning to the end of an experiment. This correction has been shown in the published theory of the method ${ }^{2}$ to be the same for both types of experiment, and, where desirable, can be determined by a third type of experiment in the same apparatus. For temperatures near the normal boiling points this correction is small compared to the quantities with which it must be combined, and its value can be calculated from specific volume and vapor pressure data more accurately than it can be measured calorimetrically.

The present series of experiments was undertaken primarily for obtaining values of latent heats, but, since it is not possible to start and finish each latent-heat experiment at identically the same temperature, the heat-sapacity experiments were necessary for the evaluation of end corrections. The values of heat content obtained from the present work are probably as precise as any now available, but are not as well established as would have been desirable had more time been available for this work and had there been a specific need for more precise values.

The theory of the method, the apparatus, and the procedure were essentially the same as those developed in the work on steam. The two reports to which reference has already been made are given in considerable detail, and it is deemed unnecessary to include a lengthy repetition here.

The apparatus is built to provide for accurately controlling, observing, and accounting for the amount, change in state, and change in energy of a sample of fluid. A single calorimetric equipment yields results which establish values of latent heat and changes in heat content of the saturated fluids in the range covered by the experiments. A schematic representation of the calorimeter is given in Figure 1.

A quantity of fluid, part liquid and part vapor, is contained in a metal calorimeter shell $(C)$. The liquid is circulated rapidly over an electric heater $(I I)$ and about the interior of the shell by a small centrifugal pump $(P)$, to distribute heat and promote close approximation to thermal equilibrium. The sample at some chosen saturation state is heated to some other chosen saturation state, or else is withdrawn as saturated vapor. Energy is added and measured electrically.

Outlets with valves provide for the introduction and withdrawal of both liquid and vapor. The line at the top $\left(L^{\prime}\right)$ is for removing vapor, and is provided with a throttle valve $\left(T^{\prime}\right)$ for controlling the rate of

I3. S. Jour. Research, 4, D. 609; 1930. 
vapor flow. Following the throttle valve in this line are three other valves $(S)$ for diverting the flow into any one of three receivers. These detachable receivers, suitable for weighing, are connected to the outlets to hold the samples of fluid transferred.

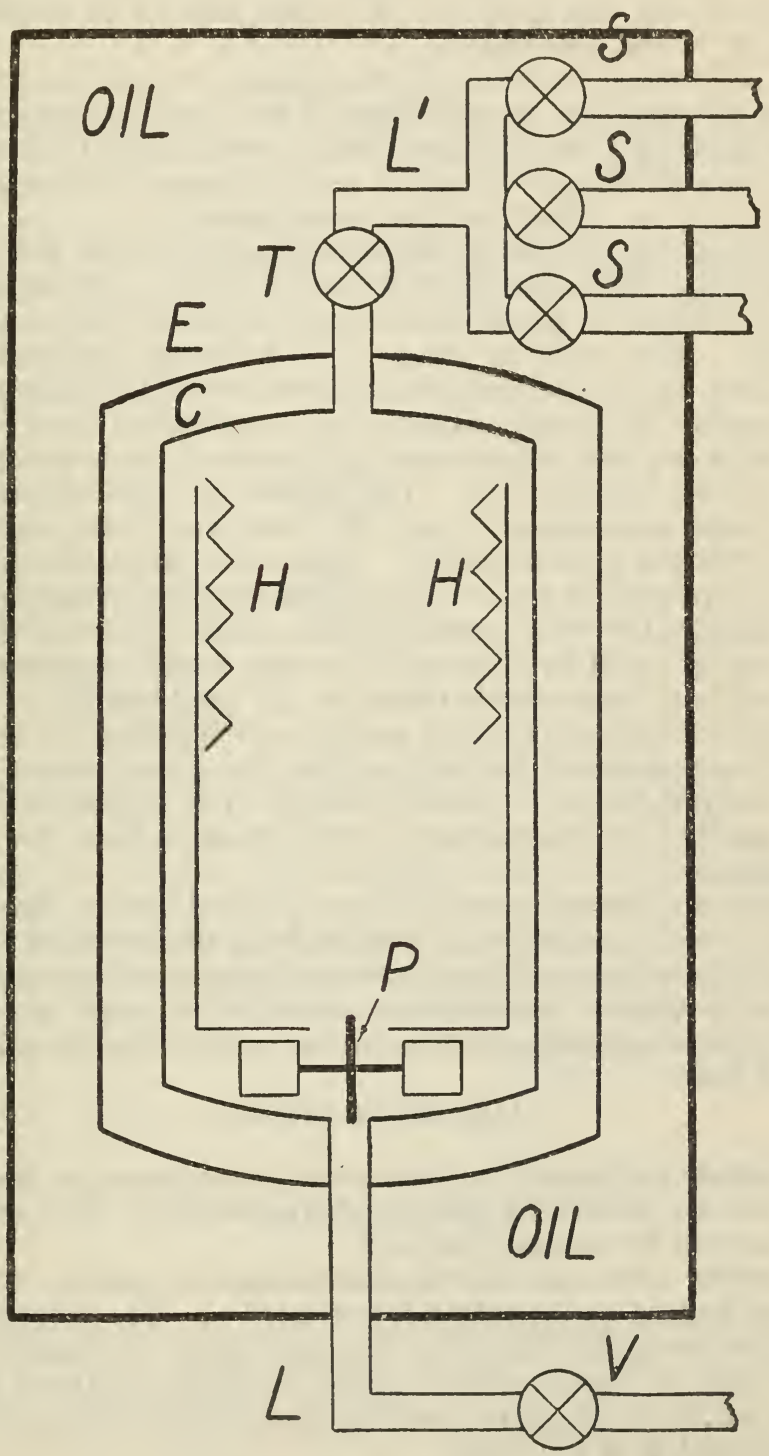

FiguRE 1.-Schematic representation of the calorimeter

The calorimeter is surrounded by an envelope $(E)$ and the intervening space is filled with nitrogen. The envelope temperature is controlled and regulated by an oil bath which surrounds the entire apparatus. 
Absolute temperatures are measured by means of a platinum resistance thermometer and small temperature differences by means of thermoelements.

In the present series of experiments the operators had the advantage of previous experience with the calorimeter. This proved useful not only in the actual manipulation, but also served as a guide in the simplification of the procedure.

During the steam research it was demonstrated that the pump energy was independent of the height of the liquid in the calorimeter, within the limit of error involved in its experimental determination. For this reason all measurements of pump energy with organic liquids were made with low fillings of the calorimeter.

The experimental values of the latent heat of water were shown to be independent of the rate of withdrawal of vapor. Hence the present series of vaporization experiments was performed at a single convenient rate. The work on steam, it is believed, demonstrates that only saturated vapor is withdrawn under normal operating conditions.

The quantity of energy passing by conduction, convection, and radiation between the calorimeter and its envelope is independent of the fluid in the calorimeter. The values of this thermal-leakage coefficient were determined during the work on steam, and were not remeasured for the present series. Because of the favorable range of temperature covered in these experiments and the greater skill which had been acquired by the operators, the actual values of the thermal leakage were so small in all cases that they could have been entirely neglected without appreciable effect on the final results.

The rate at which mechanical energy was supplied by the circulating pump was measured for each of the three compounds at several different temperatures. Curves through the experimental points made it possible to interpolate at the places where there were no determinations.

The resistance thermometer was recalibrated late in the steam program and showed no significant change from the previous calibration.

The potentiometers and electrical standards have been calibrated at frequent intervals at this bureau, and the thermal quantities are reported in international electrical units referred to the standards as maintained here.

\section{NOTATION}

The notation employed in this report is the same as that used by Osborne ${ }^{3}$ in the published theory of the method. For convenience his notation will be repeated in part.

The quantity obtained directly from a heat-capacity experiment is called $\alpha$ and from a vaporization experiment $\gamma$. The correction which takes into account the change in the proportion of liquid and vapor masses during an experiment is called $\beta$. Each of these quantities, when referred to in this paper, will be used specifically; that is, referring always to $1 \mathrm{~g}$ of the fluid.

Other quantities may be defined as follows: $H=$ hert content or enthalpy per unit mass of saturated liquid $I^{\prime}=$ hent content or enthalpy per unit mass of saturated vapor
$\left(\epsilon^{\prime}+\pi u^{\prime}\right)$. 
$\epsilon=$ internal energy per unit mass of saturated liquid.

$\epsilon^{\prime}=$ internal energy per unit mass of saturated vapor.

$L=$ latent heat of vaporization per unit mass.

$\theta=$ temperature on the international scale.

$\theta=$ temperature on the Kelvin scale.

$\pi=$ saturation vapor pressure.

$u=$ specific volume of saturated liquid.

$u^{\prime}=$ specific volume of saturated vapor.

$Q=$ total energy added to the calorimeter in any experiment.

$Z=$ a constant of the calorimeter depending on its temperature and the liquid it contains.

$M=$ total mass of fluid in the calorimeter.

As shown in the published theory, the following thermodynamic relations may be used to reduce the quantities actually observed to those more commonly employed.

$$
\begin{aligned}
H & =\alpha+\beta \\
L & =\gamma-\beta \\
\gamma & =L \frac{u^{\prime}}{u^{\prime}-u}=\theta u^{\prime} \frac{d \pi}{d \theta} \\
\beta & =L \frac{u}{u^{\prime}-u}=\theta u \frac{d \pi}{d \theta} \\
H^{\prime} & =H+L \\
Q & =Z+M \alpha \\
\gamma_{1} & =\frac{1}{\Delta M}\left\{Q-\left[Z+M_{2} \alpha\right]_{1}^{2}+\int_{1}^{2}\left(H-H_{1}\right) d M\right\}
\end{aligned}
$$

The values of $H$ and $L$ were obtained from the experimental values of $\alpha$ and $\gamma$ and the values of $\beta$ calculated from other data with the aid of the second form of equation (4).

The absolute value of $H$ can not be determined, but any arbitrary datum may be chosen within the temperature range covered by the experiments, and values of $H$ at other temperatures in the range can be established relative to the datum. Adoption of a datum for $H$ simultaneously fixes a reference value for $\alpha$.

\section{PREPARATION AND PHYSICAL PROPERTIES OF COMPOUNDS}

\section{METHYL ALCOHOL}

Mallinckrodt's methyl alcohol, specially ordered as chloroform free, was distilled by Dr. J. H. Bruun, of the chemistry division of this bureau, in a nonsiphoning, 30-plate, bubbling-cap still ${ }^{4}$ to remove water and other impurities which can be separated by fractional distillation. The middle fraction of $1,000 \mathrm{~cm}^{3}$ was used from a charge of $2,500 \mathrm{~cm}^{3}$ which was introduced into the still pot. The distillation was performed in an atmosphere of dry carbon dioxide at approximately atmospheric pressure. The distillate was collected in a bottle filled initially with dry air and was stored in a dessicator. Provision was made for transferring the liquid without further contact with the

1 Ind. Eng. Chem., Anal. ed., 1, p. 212; October, 1929. 
air to a second still, which could be used both for refluxing and distilling. Here the sample was freed from dissolved gases by repeated refluxing, cooling, and evacuation. After thus pumping off the dissolved gas, the sample was distilled under its own vapor pressure at a temperature of about $50^{\circ}$ C., and collected in evacuated silver containers. From these it was transferred to the calorimeter.

The specific gravity of the gas-free product, before its use in the calorimeter, was measured by the volumetric section of this bureau. 'To avoid contact with the atmosphere the alcohol was introduced into an evacuated picnometer through an evacuated line. The volume of the picnometer was about $87 \mathrm{~cm}^{3}$, and the samples used therein were always discarded. The observed specific gravity at $20^{\circ} \mathrm{C}$. compared to water at $4^{\circ} \mathrm{C}$. was $\mathrm{D}_{4}^{20}=0.79133$. According to the International Critical Tables, vol. 3, p. 27, Klason and Norlin give as their value for absolute methyl alcohol $\mathrm{D}_{4}^{20}=0.79134$.

An accurate combustion analysis of the original material was made by Dr. F. D. Rossini, of the chemistry division of this bureau. This analysis showed that the carbon-hydrogen ratio was that required by the formula $\mathrm{CH}_{3} \mathrm{OH}$, within the limit of error of the analysis, which was \pm 0.03 per cent.

After the completion of a vaporization experiment the sample was in four containers, and had to be reassembled before being weighed into the calorimeter again. This was accomplished by transfer under its own vapor pressure through an evacuated line, without any contact with the atmosphere. Such a procedure made possible the performance of the whole series of calorimetric experiments on an original sample of about $350 \mathrm{~g}$.

At one stage in the experiments with methyl alcohol a leak developed in the lower tube leading to the calorimeter. This permitted contact of a portion of the sample with the atmosphere. This portion was again freed from dissolved gas, but contained a small amount of water. For the remainder of the experiments the entire sample of alcohol was reunited, since the amount of water which could have been taken from the air was known to be small.

After the completion of the calorimetric experiments the specific gravity of the assembled sample was again measured and the value obtained was $D_{4}^{20}=0.79142$.

The increase in specific gravity was thus 0.00009 , corresponding, if the impurity was all water, to about 0.026 per cent of water by weight. This fraction of water would produce no measurable effect on the values of $\alpha$ and would correspond to an increase in $\gamma$ of only about 3 parts in 10,000 . Since this is well within the experimental uncertainty involved, it was deemed unnecessary to repeat the experiments with another sample of alcohol.

\section{ETHYL ALCOHOL}

Through the courtesy of Dr. F. M. Hildebrandt, the United States Industrial Alcohol Co. furnished an especially selected sample of ethyl alcohol (192 volume proof) having a very low aldehyde content.

Most of the water present was removed by refluxing and distilling from an excess of freshly ignited lime at atmospheric pressure. About 2,500 $\mathrm{cm}^{3}$ of alcohol, whose specific gravity indicated a water content of 0.15 per cent by weight, were prepared by this method. 
This 2,500 $\mathrm{cm}^{3}$ sample, together with $40 \mathrm{~cm}^{3}$ of 'Timmermans' benzene, which will be described later, was introduced into a still similar to that used for fractionating the methyl alcohol.

The remainder of the water was removed from this mixture by fractional distillation. The first fraction to distil consists of a constant boiling mixture of benzene, alcohol, and water. When all the water has been removed, a constant boiling binary mixture of benzene and alcohol continues to distil as long as any benzene remains. Since the indices of refraction of benezne and alcohol are so widely different, this property was used as a criterion for the complete removal of the benzene. About $250 \mathrm{~cm}^{3}$ were rejected after the index of the distillate became constant. The next $900 \mathrm{~cm}^{3}$ which distilled were used as the best product of the fractionation.

The method of collecting the sample and of removing dissolved gases from it was the same as that described for methyl alcohol. The specific gravity of the gas-free product was found to be $\mathrm{D}_{4}^{20}=$ 0.78946. According to the International Critical Tables, vol. 3, p. 27, Osborne, McKelvy, and Bearce give as their best value for absolute ethyl alcohol $D_{4}^{20}=0.78934$. If water was the only impurity the initial sample contained 0.038 per cent by weight. The specific gravity of the alcohol which had been used in the entire series of observations was $\mathrm{D}_{4}^{20}=0.78949$, indicating 0.047 per cent of water by weight. The effect of this quantity of water on the measured values of latent heat could not have been greater than 0.6 joule per gram, or 1 part in 1,400 of the total.

\section{BENZENE}

About $1,000 \mathrm{~cm}^{3}$ of benzene prepared by Timmermans and Martin ${ }^{5}$ at the International Bureau of Physico-Chemical Standards at Brussels were refluxed for three hours with about $15 \mathrm{~g}$ of a $50-50 \mathrm{~mol}$ per cent sodium-potassium alloy. This alloy was furnished by Dr. O. C. Bridgeman, of this bureau, who had prepared it in very pure form for use in determining quantitatively the water content of gasolines.

The benzene was introduced into an apparatus which could be used both for refiuxing and distilling. After it had been frozen and the permanent gas present removed by pumping, the alloy was introduced. After refluxing for a time the benzene was again frozen, and the gas evolved on boiling was pumped off. This process was reperted four times, the amount of noncondensible gas coming off the last time being practically nil.

After three hours of refluxing, during which numerous droplets of liquid alloy were in vigorous circulation within the liquid benzene, the benzene was distilled under its own vapor pressure at a temperature of about $50^{\circ} \mathrm{C}$., and collected in evacuated silver containers.

The specific gravity of the air-free product was not measured before the calorimetric experiments because a sufficient quantity could not be spared. After the measurements were completed, specific gravities were measured on two samples which had been distilled from the

B J. chim. phys., 23, p. 18; 1926. 
calorimeter, and on the residue left in it after a series of vaporization experiments. The values of $\mathrm{D}_{4}^{20}$ obtained were 0.87906 and 0.87907 for the distillate and 0.87906 for the residue.

The recorded determinations of the specific gravity of benzene at $20^{\circ}$ C. vary from 0.8787 to 0.8795 , with those which seem more reliable averaging about 0.8790 . From specific-gravity measurements alone it is difficult to estimate the purity of benzene for want of a well-established reference value.

The product used in these experiments was prepared from the source which, according to our advices, was the best available. The water content was probably reduced to well below 0.01 per cent. The presence of homologs of benezene in minute quantities would have produced no measurable effects on the thermal properties observed.

\section{RESULTS OF MEASUREMENTS}

In the following record of these measurements the results have been assembled in the form of tables. An explanation of the mechanism of the reduction of the quantities observed to the properties desired is given in the report on the work on steam. ${ }^{6}$

Three complete sets of $\alpha$ experiments were performed with a large mass and three with a small mass of fluid in the calorimeter. The experiments did not start and stop at exactly the even $10^{\circ}$ temperatures so the measured values of $Q$ were corrected to the even intervals for convenience. From curves of $\frac{\Delta Q}{\Delta \theta}$ plotted against temperature, the small corrections to the even $10^{\circ}$ points were determined, and these corrections, applied to the measured values of $Q$, yielded the values of $Q]_{1}^{2}$ corrected to the even temperature intervals.

Choosing for example the interval $40^{\circ}$ to $50^{\circ}$, the value of the change in $\alpha$ for the liquid was computed for this interval as follows. For each observed value of $Q]_{40}^{50}$ there is an observed mass $M$ of fluid in the calorimeter system. To determine the values of the two constants $Z$ and $\alpha$ in the equation.

$$
\left.\left.Q]_{40}^{50}=Z\right]_{40}^{50}+M \alpha\right]_{40}^{50}
$$

the method of least squares was employed. As an indication of the consistency of the results, the value of $Z]_{40}^{50}$ so obtained was used for the computation of the value of $\alpha$ indicated by each individual experiment. The tabulated values of $\alpha_{m}$ are the values obtained by the method of least squares, and the other values of $\alpha$ were computed for the separate determinations as just described. The results of the $\alpha$ experiments are shown in Table 1.

- See lootnote 1, p. 881. 
TABLE 1.-Results of $\alpha$ experiments

$$
\alpha]_{1}^{2}=\left[H-L \frac{u}{u^{\prime}-u}\right]_{1}^{2}
$$

\begin{tabular}{|c|c|c|c|c|c|c|}
\hline \multirow{2}{*}{ Temperature interval $\left({ }^{\circ} \mathrm{C}\right.$.) } & \multicolumn{2}{|c|}{ Methyl alcohol } & \multicolumn{2}{|c|}{ Ethyl alcohol } & \multicolumn{2}{|c|}{ Benzene } \\
\hline & $\alpha]_{1}^{2}$ & $\alpha]_{1}^{2}-\alpha_{m}$ & $\alpha]_{1}^{2}$ & $\alpha]_{1}^{2}-\alpha_{m}$ & $\alpha]_{1}^{2}$ & $\alpha]_{1}^{2}-\alpha_{m}$ \\
\hline \multirow{3}{*}{$\alpha_{m}=\ldots \ldots \ldots \ldots$} & $\begin{array}{r}\text { Int. J./g } \\
26.075 \\
26.075 \\
26.089 \\
26.087 \\
26.068 \\
26.084 \\
\end{array}$ & $\begin{array}{r}\text { Int. } J . / g \\
-0.005 \\
-.005 \\
.009 \\
.007 \\
-.012 \\
.004\end{array}$ & $\begin{array}{r}\text { Int. J./g } \\
26.025 \\
26.030 \\
26.057 \\
26.023 \\
26.061 \\
26.028\end{array}$ & $\begin{array}{r}\text { Int. J./g } \\
-0.012 \\
-.007 \\
.020 \\
-.014 \\
.024 \\
-.009\end{array}$ & \begin{tabular}{|c} 
Int. J./g \\
\end{tabular} & Int. J./g \\
\hline & 26.080 & - - & 26.037 & - n...... & - & $\ldots$ \\
\hline & $\begin{array}{l}26.799 \\
26.847 \\
26.808 \\
26.807 \\
26.816 \\
26.829 \\
\end{array}$ & $\begin{array}{r}-.019 \\
.029 \\
-.010 \\
-.011 \\
-.002 \\
.011 \\
\end{array}$ & $\begin{array}{l}26.906 \\
26.918 \\
26.944 \\
26.908 \\
26.920 \\
26.940 \\
\end{array}$ & $\begin{array}{r}-.016 \\
-.004 \\
.022 \\
-.014 \\
-.002 \\
.018 \\
\end{array}$ & $\begin{array}{l}18.340 \\
18.290 \\
18.279 \\
18.280 \\
18.319 \\
18.310 \\
\end{array}$ & $\begin{array}{r}0.037 \\
-.013 \\
-.024 \\
-.023 \\
.016 \\
.007 \\
\end{array}$ \\
\hline \multirow{3}{*}{$\alpha_{\mathrm{m}}=$} & 26.818 & -........ & 26. 922 & -....... & 18. 303 & $-\ldots-\ldots$ \\
\hline & $\begin{array}{l}27.567 \\
27.512 \\
27.557 \\
27.520 \\
27.553 \\
27.564 \\
\end{array}$ & $\begin{array}{r}.021 \\
-.034 \\
.011 \\
-.026 \\
.007 \\
.018 \\
\end{array}$ & $\begin{array}{l}27.986 \\
27.967 \\
27.992 \\
27.990 \\
27.960 \\
27.995 \\
\end{array}$ & $\begin{array}{r}.004 \\
-.015 \\
.010 \\
.008 \\
-.022 \\
.013 \\
\end{array}$ & $\begin{array}{l}18.546 \\
18.554 \\
18.546 \\
18.582 \\
18.513 \\
18.568 \\
\end{array}$ & $\begin{array}{r}.010 \\
.000 \\
-.008 \\
.028 \\
-.041 \\
.014 \\
\end{array}$ \\
\hline & 27.546 & .......... & 27.982 & ......... & 18.554 & ........ \\
\hline \multirow{2}{*}{$\alpha_{m}=$} & $\begin{array}{l}28.208 \\
28.223 \\
28.204 \\
28.262 \\
28.176 \\
28.197 \\
\end{array}$ & $\begin{array}{r}-.004 \\
.011 \\
-.008 \\
.050 \\
-.036 \\
-.015 \\
\end{array}$ & $\begin{array}{l}29.045 \\
29.033 \\
29.026 \\
29.017 \\
29.073 \\
29.041 \\
\end{array}$ & $\begin{array}{r}.006 \\
-.006 \\
-.013 \\
-.022 \\
.034 \\
.002 \\
\end{array}$ & $\begin{array}{l}18.782 \\
18.764 \\
18.757 \\
18.726 \\
18.792 \\
18.785 \\
\end{array}$ & $\begin{array}{r}.014 \\
-.004 \\
-.011 \\
-.042 \\
.024 \\
.017 \\
\end{array}$ \\
\hline & 28.212 & - & 29.039 & (n-...- & 18. 768 & -........ \\
\hline \multirow{2}{*}{$\alpha_{m}=$} & $\begin{array}{l}28.866 \\
28.874 \\
28.868 \\
28.892 \\
28.854 \\
28.862 \\
\end{array}$ & $\begin{array}{r}-.003 \\
.005 \\
-.001 \\
.023 \\
-.015 \\
-.007 \\
\end{array}$ & $\begin{array}{l}30.026 \\
29.996 \\
30.042 \\
29.999 \\
30.058 \\
30.007 \\
\end{array}$ & $\begin{array}{r}.005 \\
-.025 \\
.021 \\
-.022 \\
.037 \\
-.014 \\
\end{array}$ & $\begin{array}{l}19.012 \\
18.998 \\
18.999 \\
18.968 \\
19.022 \\
19.019 \\
\end{array}$ & $\begin{array}{r}.009 \\
-.005 \\
-.004 \\
-.035 \\
.019 \\
.016 \\
\end{array}$ \\
\hline & 28.869 & (n...... & 30.021 & (n) & 19.003 & (n) \\
\hline \multirow{2}{*}{$\alpha_{m}=$} & $\begin{array}{l}29.704 \\
29.651 \\
29.656 \\
29.693 \\
29.667 \\
29.650 \\
\end{array}$ & $\begin{array}{r}.034 \\
-.019 \\
-.014 \\
.023 \\
-.003 \\
-.020 \\
\end{array}$ & $\begin{array}{l}31.316 \\
31.309 \\
31.259 \\
31.327 \\
31.288 \\
31.269 \\
\end{array}$ & $\begin{array}{r}.021 \\
.014 \\
-.036 \\
.032 \\
-.007 \\
-.026 \\
\end{array}$ & $\begin{array}{l}19.284 \\
19.262 \\
19.235 \\
19.295 \\
19.239 \\
19.247 \\
\end{array}$ & $\begin{array}{r}.024 \\
.002 \\
-.025 \\
.035 \\
-.021 \\
-.013 \\
\end{array}$ \\
\hline & 29.670 & (n) & 31.295 & - & 19. 260 & (n....... \\
\hline \multirow[t]{2}{*}{$100-110 \ldots$} & $\begin{array}{l}30.338 \\
30.313 \\
30.302 \\
30.340 \\
30.302 \\
30.311 \\
\end{array}$ & $\begin{array}{r}.020 \\
-.005 \\
-.016 \\
.022 \\
-.016 \\
-.007 \\
\end{array}$ & $\begin{array}{l}\text { 32. } 208 \\
32.220 \\
32.258 \\
32.209 \\
32.231 \\
32.246\end{array}$ & $\begin{array}{r}-.021 \\
-.009 \\
.029 \\
-.020 \\
.002 \\
.017 \\
\end{array}$ & $\begin{array}{l}19.501 \\
19.501 \\
19.488 \\
19.504 \\
19.490 \\
19.496 \\
\end{array}$ & $\begin{array}{r}.004 \\
.004 \\
-.009 \\
.007 \\
-.067 \\
-.001 \\
\end{array}$ \\
\hline & 30.318 & & 32. 229 & & 19.497 & \\
\hline
\end{tabular}

Before continuing further with the reduction of the data from the heat-capacity determinations, the results of the $\gamma$ experiments will be tabulated. The values of $\gamma$ were calculated from equation (7), in which $\gamma_{1}$ is the value of $\gamma$ at the initial temperature and $\Delta M$ represents the mass of vapor removed. The quantity $\left[Z+M_{2} \alpha\right]_{1}^{2}$ is that energy quantity involved in a change in calorimeter temperature from the initial to a different final value. The values of $Z$ and $\alpha$ are available 
from the results of the $\alpha$ experiments, and that of $M_{2}$, the mass remaining in the calorimeter at the completion of a $\gamma$ experiment, is known from the weighings. The quantity $\int_{1}{ }^{2}\left(H-H_{1}\right) d M$ represents the energy involved in a change in the temperature of the vapor leaving the calorimeter during an experiment. It is negligibly small under the steady temperature conditions which prevailed during the present work. It is mentioned only for consistency with the exact theory.

The results of the $\gamma$ experiments are assembled in Table 2. The corrections of the observed values of $\gamma_{1}$ to the desired temperatures involved graphical determinations of $\frac{d \gamma}{d \theta}$. The corrections are very small because the values of $\theta_{1}$ were so near to the temperatures recorded.

TABLE 2.-Results of $\gamma$ experiments

$$
\gamma=\frac{L u^{\prime}}{u^{\prime}-u}
$$

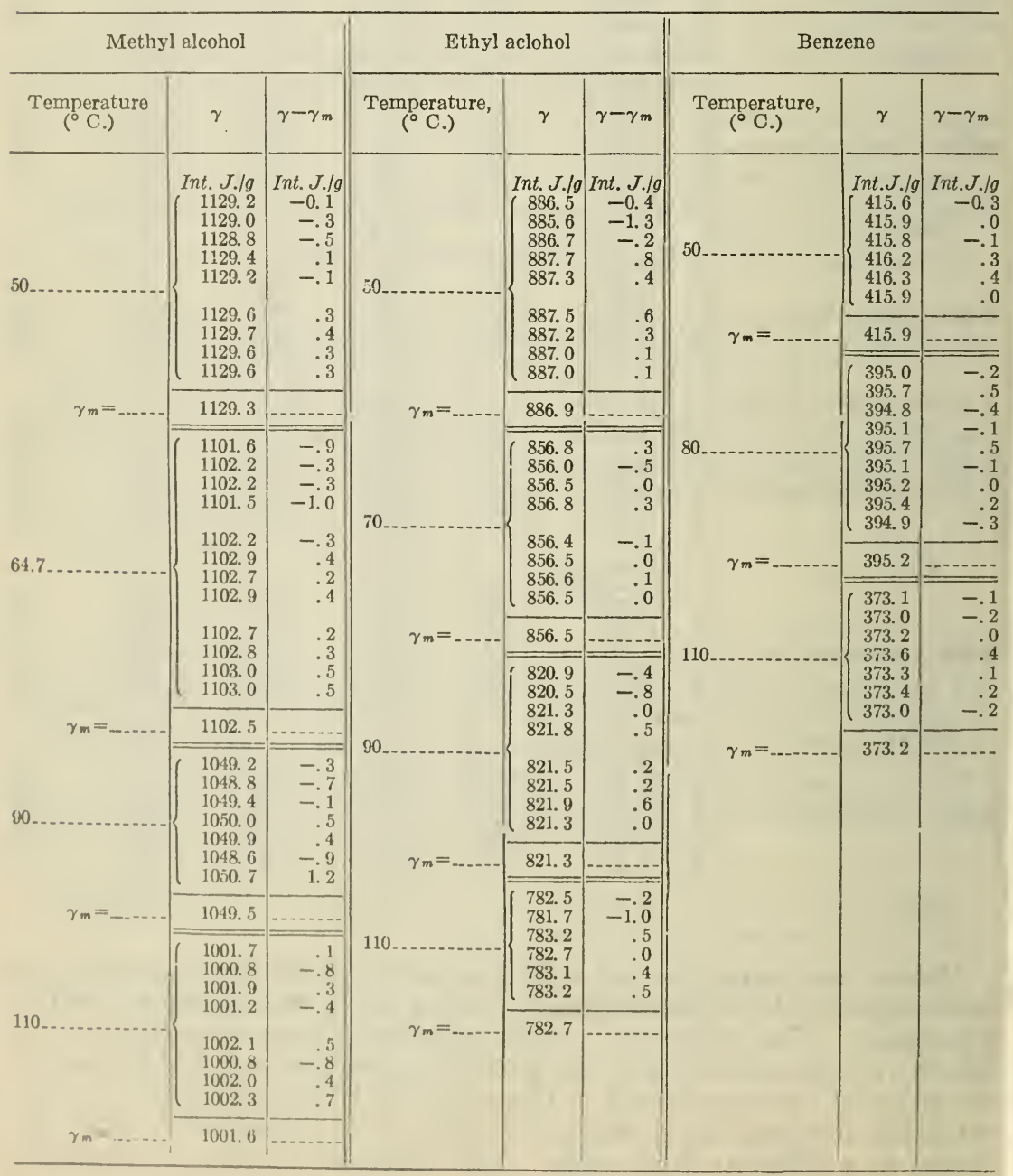


To reduce the values of $\alpha$ and $\gamma$ to the desired quantities $H$ and $L$, it is necessary to evaluate the correction term $\beta$ throughout the range of the experiments. Since $\beta$ is small in this range, it is believed that its values can be calculated more accurately from vapor pressure and specific volume data than they could be measured calorimetrically.

All terms in the right-hand member of the equation $\beta=\theta u \frac{d \pi}{d \theta}$ were evaluated for each of the substances concerned from the results of measurements made by Young. ${ }^{7} \quad$ Values of $\frac{d \pi}{d \theta}$ were calculated by differentiation of his vapor pressure equations. Table 3 shows the quantities taken from the work of Young and the values of $\beta$ computed therefrom at those temperatures where they are needed in the further reduction of the data.

TABLE 3.-Calculation of values of $\beta$

$$
\beta=\Theta u \frac{d \pi}{d \theta}
$$

[1 liter-atmosphere $=101.29$ international joules]

\begin{tabular}{|c|c|c|c|c|c|c|c|c|c|c|}
\hline \multicolumn{2}{|c|}{ Temperature } & \multicolumn{3}{|c|}{ Methyl alcohol } & \multicolumn{3}{|c|}{ Ethyl alcohol } & \multicolumn{3}{|c|}{ Benzene } \\
\hline$\theta$ & $\theta$ & $u \times 10^{3}$ & $\frac{d \pi}{d \theta}$ & $\boldsymbol{\beta}$ & $u \times 10^{3}$ & $\frac{d \pi}{d \theta}$ & $\beta$ & $u \times 10^{3}$ & $\frac{d \pi}{d \theta}$ & $\beta$ \\
\hline $\begin{array}{r}{ }^{\circ} C_{i} \\
0 \\
10 \\
20 \\
25\end{array}$ & $\begin{array}{l}{ }^{\circ} \mathrm{K} . \\
273.1 \\
283.1 \\
293.1 \\
298.1\end{array}$ & $\begin{array}{r}\text { Liters/g } \\
1.2345 \\
1.2489 \\
1.2637 \\
1.2713\end{array}$ & $\begin{array}{r}\text { Atm./deg. } \\
0.00245 \\
.00416 \\
.00677 \\
.00852\end{array}$ & $\begin{array}{r}\text { Int. J./g } \\
0.08 \\
.15 \\
.25 \\
.33\end{array}$ & $\begin{array}{r}\text { Liters/g } \\
1.2403 \\
1.2534 \\
1.2669 \\
1.2738\end{array}$ & $\begin{array}{c}\text { Atm./deg. } \\
0.00111 \\
.00200 \\
.00344 \\
.00443\end{array}$ & $\begin{array}{r}\text { Int. J./g } \\
0.04 \\
.07 \\
.13 \\
.17\end{array}$ & $\begin{array}{c}\text { Liters/g } \\
(1.1110) \\
1.1243 \\
1.1380 \\
1.1449\end{array}$ & $\begin{array}{c}\text { Atm./deg. } \\
(0.0020) \\
.00309 \\
.00469 \\
.00568\end{array}$ & $\begin{array}{c}\text { Int. J./g } \\
(0.06) \\
.10 \\
.16 \\
.20\end{array}$ \\
\hline $\begin{array}{l}30 \\
40 \\
50 \\
60\end{array}$ & $\begin{array}{l}303.1 \\
313.1 \\
323.1 \\
333.1\end{array}$ & $\begin{array}{l}1.2780 \\
1.2948 \\
1.3111 \\
1.3240\end{array}$ & $\begin{array}{l}.01061 \\
.01606 \\
.02353 \\
.03355\end{array}$ & $\begin{array}{r}.41 \\
.65 \\
1.00 \\
1.48\end{array}$ & $\begin{array}{l}1.2808 \\
1.2953 \\
1.3104 \\
1.3261\end{array}$ & $\begin{array}{l}.00570 \\
.00907 \\
.01394 \\
.02073\end{array}$ & $\begin{array}{l}.22 \\
.37 \\
.59 \\
.92\end{array}$ & $\begin{array}{l}1.1520 \\
1.1664 \\
1.1813 \\
1.1967\end{array}$ & $\begin{array}{l}.00688 \\
.00978 \\
.01350 \\
.01814\end{array}$ & $\begin{array}{l}.24 \\
.36 \\
.52 \\
.72\end{array}$ \\
\hline $\begin{array}{l}64.7 \\
70 \\
80 \\
90\end{array}$ & $\begin{array}{l}337.8 \\
343.1 \\
353.1 \\
363.1\end{array}$ & $\begin{array}{l}\text { 1. } 3362 \\
\text { 1. } 3405 \\
\text { 1. } 3600 \\
1.3790\end{array}$ & $\begin{array}{l}.03917 \\
.04651 \\
.06302 \\
.08359\end{array}$ & $\begin{array}{l}1.77 \\
2.14 \\
3.03 \\
4.19\end{array}$ & $\begin{array}{l}\text { 1. } 3430 \\
\text { 1. } 3609 \\
1.3791\end{array}$ & $\begin{array}{l}.02989 \\
.04192 \\
.05729\end{array}$ & $\begin{array}{l}1.38 \\
2.01 \\
2.87\end{array}$ & $\begin{array}{l}\text { 1. } 2126 \\
\text { 1. } 2278 \\
1.2436\end{array}$ & $\begin{array}{l}.02383 \\
.03064 \\
.03865\end{array}$ & $\begin{array}{l}.99 \\
1.33 \\
1.75\end{array}$ \\
\hline $\begin{array}{l}100 \\
110 \\
120 \\
130\end{array}$ & $\begin{array}{l}373.1 \\
383.1 \\
393.1 \\
403.1\end{array}$ & $\begin{array}{l}1.401 \\
1.424 \\
1.449 \\
1.477\end{array}$ & $\begin{array}{l}.1088 \\
.1391 \\
.1751 \\
.2174\end{array}$ & $\begin{array}{r}5.69 \\
7.59 \\
9.97 \\
13.11\end{array}$ & $\begin{array}{l}1.397 \\
1.417 \\
1.444 \\
1.473\end{array}$ & $\begin{array}{l}.07648 \\
.0999 \\
.1280 \\
.1612\end{array}$ & $\begin{array}{l}3.99 \\
5.42 \\
7.27 \\
9.69\end{array}$ & $\begin{array}{l}1.262 \\
1.281 \\
1.300 \\
1.321\end{array}$ & $\begin{array}{l}.04794 \\
.05857 \\
.07059 \\
.08407\end{array}$ & $\begin{array}{l}\text { 2. } 26 \\
2.87 \\
3.61 \\
4.53\end{array}$ \\
\hline
\end{tabular}

Table 4 gives the values of $L$ computed from the mean experimental values, $\gamma_{\mathrm{m}}$, by the relation $L=\gamma-\beta$.

TABLE 4.-Computation of latent heats

$$
L=\gamma-\beta
$$

\begin{tabular}{|c|c|c|c|c|c|c|c|c|c|}
\hline \multirow{2}{*}{$\begin{array}{l}\text { Temper- } \\
\text { ature } \theta\end{array}$} & \multicolumn{3}{|c|}{ Methyl alcohol } & \multicolumn{3}{|c|}{ Ethyl alcohol } & \multicolumn{3}{|c|}{ Benzene } \\
\hline & $\boldsymbol{\gamma}$ & $\beta$ & $L$ & $\gamma$ & $\beta$ & $L$ & $\gamma$ & $\beta$ & $L$ \\
\hline${ }^{\circ}{ }^{\circ} \mathrm{C}$. & $\begin{array}{l}\text { Int. J./O } \\
1,129.3\end{array}$ & Int. $J . / g$ & $\begin{array}{r}\text { Int. J./g } \\
1,128.3 \\
1,100.7\end{array}$ & $\begin{array}{c}\text { Int. J./g } \\
886.9\end{array}$ & Int. $\mathrm{J}_{0.6} . \mathrm{g}$ & $\begin{array}{r}\text { Int. J./g } \\
886.3\end{array}$ & $\begin{array}{r}\text { Int. J./g } \\
415.9\end{array}$ & Int. J./g & $\begin{array}{c}\text { Int. J./g } \\
415.4\end{array}$ \\
\hline 70 & $\begin{array}{r}1,102.0 \\
\ldots . . .6 . . .\end{array}$ & 1.0 & $1,100$. & 856.5 & 1.4 & 855.1 & & & \\
\hline $\begin{array}{l}80 \\
90\end{array}$ & $1,049.5$ & 42 & 1.045 .8 & 8213 & 29 & 818.4 & 395.2 & 1.3 & 393.9 \\
\hline 110 & $1,001.6$ & 7.6 & 994.0 & 782.7 & 5.4 & 777.3 & 373.2 & $\ddot{2} . \ddot{8}$ & 3708 \\
\hline
\end{tabular}

7 Proc. Roy. Dublin Soc., 12, p. 374; 1910.

$49527^{\circ}-31-9$ 
To facilitate the interpolation and extrapolation of the values of latent heat, an empirical equation expressing $L$ as a function of $\theta$ was fitted to the observed values for each of the substances. The type chosen for these equations was the same as that which proved adequate to represent the experimental values for water. Each equation requires that the latent heat approach zero at the critical temperature $\theta_{c}$ at a negatively infinite rate, and that no real values exist above this temperature. Table 5 gives the values of $L$ calculated from the equations which appear below the columns of figures.

TABLE 5.-Formulation of latent heat values

\begin{tabular}{|c|c|c|c|c|c|c|}
\hline \multirow{3}{*}{$\begin{array}{l}\text { Temper- } \\
\text { ature } \\
\theta\end{array}$} & \multicolumn{2}{|c|}{ Methyl alcohol } & \multicolumn{2}{|c|}{ Ethyl alcohol } & \multicolumn{2}{|c|}{ Benzene } \\
\hline & \multicolumn{6}{|c|}{ Latent heat of vaporization } \\
\hline & Observed & Equation & Observed & Equation & Observed & Equation \\
\hline $\begin{array}{c}{ }^{\circ} C . \\
0 \\
10 \\
20 \\
25\end{array}$ & Int. J./g & $\begin{array}{c}\text { Int. J./g } \\
1(1,200.1) \\
(1,188.5) \\
(1,175.4) \\
(1,168.4)\end{array}$ & Int. J./g & $\begin{array}{c}\text { Int. J./g } \\
(946.0) \\
(936.2) \\
(925.4) \\
(919.6)\end{array}$ & Int. J./g & $\begin{array}{c}\text { Int. J./g } \\
(447.2) \\
(441.2) \\
(435.0) \\
(431.9)\end{array}$ \\
\hline $\begin{array}{l}30 \\
40 \\
50 \\
60\end{array}$ & $1,128.3$ & $\begin{array}{c}(1,161.0) \\
(1,145.3) \\
1,128.2 \\
1,109.7\end{array}$ & 886.3 & $\begin{array}{c}(913.5) \\
(900.5) \\
886.5 \\
871.3\end{array}$ & 415.4 & $\begin{array}{c}(428.7) \\
(422.1) \\
415.4 \\
408.4\end{array}$ \\
\hline $\begin{array}{l}64.7 \\
70 \\
80 \\
90\end{array}$ & $\begin{array}{l}1,100.7 \\
1,045.3\end{array}$ & $\begin{array}{l}1,100.5 \\
1,089.8 \\
1,068.3 \\
1,045.2\end{array}$ & 855.1 & $\begin{array}{l}854.9 \\
837.3 \\
818.5\end{array}$ & 393.9 & $\begin{array}{l}401.3 \\
393.9 \\
386.3\end{array}$ \\
\hline $\begin{array}{l}100 \\
110 \\
120 \\
130\end{array}$ & 994.0 & $\begin{array}{c}1,020.5 \\
994.1 \\
(965.9) \\
(935.7)\end{array}$ & 777.3 & $\begin{array}{c}798.4 \\
777.0 \\
(754.0) \\
(729.6)\end{array}$ & $\begin{array}{r}370.3 \\
\end{array}$ & $\begin{array}{c}378.4 \\
370.3 \\
(361.9) \\
(353.2)\end{array}$ \\
\hline
\end{tabular}

1 Values in parentheses are outside the range of the experiments.

For methyl alcohol

For ethyl al $L=-0.005(240-\theta)^{2}+2.60875(240-\theta)+219(240-\theta)^{1 / 4}$

For benzene $L=-0.004067(240-\theta)^{2}+2.198(240-\theta)+165.83(240-\theta)^{1 / 4}$

$L=-0.00056185(290-\theta)^{2}+0.65028(290-\theta)+74.11(290-\theta)^{1 / 4}$

The values of the changes in heat content as shown in Table 6 follow directly from the data of Tables 1 and 3, through the equation

$$
\left.\left.H]_{1}^{2}=\alpha\right]_{1}^{2}+\beta\right]_{1}^{2} \text {. }
$$

TABIE 6.-Computation of changes in heat content

$$
\left.\left.H]_{1}^{2}=\alpha\right]_{1}^{2}+\beta\right]_{1}^{2}
$$

\begin{tabular}{|c|c|c|c|c|c|c|c|c|c|}
\hline \multirow{2}{*}{$\underset{\theta}{\substack{\text { Temper } \\
\text { ature }}}$} & \multicolumn{3}{|c|}{ Methyl alcohol } & \multicolumn{3}{|c|}{ Ethyl alcohol } & \multicolumn{3}{|c|}{ Benzene } \\
\hline & $\alpha]_{40}^{\theta}$ & $\beta]_{40}^{\theta}$ & $I I]_{t 0}^{\theta}$ & $\alpha]_{t 0}^{\theta}$ & $\beta]_{40}^{\theta}$ & $H]_{40}^{\theta}$ & $\alpha]_{50}^{\theta}$ & $\beta]_{50}^{\theta}$ & $H]_{50}^{\theta}$ \\
\hline${ }^{\circ} C_{40}$ & Int. $J .10$ & Int. J./g & Int. $J .10$ & & Int. J./g & Int. J./g & Int. J./g & Int. J./g & Int. J. 10 \\
\hline $\begin{array}{l}50 \\
60 \\
70\end{array}$ & $\begin{array}{l}26.08 \\
52.90 \\
80.44\end{array}$ & $\begin{array}{r}.35 \\
.83 \\
1.49\end{array}$ & $\begin{array}{l}26.43 \\
53.73 \\
81.93\end{array}$ & $\begin{array}{l}26.04 \\
52.96 \\
80.94\end{array}$ & $\begin{array}{r}.22 \\
.55 \\
1.01\end{array}$ & $\begin{array}{l}26.26 \\
53.51 \\
81.95\end{array}$ & $\begin{array}{l}0.00 \\
18.30 \\
36.86\end{array}$ & $\begin{array}{r}0.00 \\
.20 \\
.47\end{array}$ & $\begin{array}{r}0.00 \\
18.50 \\
37.33\end{array}$ \\
\hline $\begin{array}{r}80 \\
90 \\
100 \\
110\end{array}$ & $\begin{array}{l}108.66 \\
137.52 \\
167.20 \\
197.51\end{array}$ & $\begin{array}{l}2.38 \\
3.54 \\
5.04\end{array}$ & $\begin{array}{l}111.04 \\
141.06\end{array}$ & $\begin{array}{l}109.98 \\
140.00\end{array}$ & $\begin{array}{l}1.64 \\
2.50 \\
3.62\end{array}$ & $\begin{array}{l}111.62 \\
112.50\end{array}$ & $\begin{array}{r}55.62 \\
74.63 \\
93.89\end{array}$ & $\begin{array}{r}.81 \\
1.23 \\
1.74 \\
.35\end{array}$ & $\begin{array}{r}56.43 \\
75.86 \\
95.63 \\
15\end{array}$ \\
\hline & & & & & & & & 2. 35 & 115.73 \\
\hline
\end{tabular}


Empirical equations in the form of power series have been fitted to these values of $H]_{1}^{2}$. These equations are shown in Table 7 , together with a comparison of the experimental values with those calculated from the equations.

TABLE 7.-Formulation of neat content values

\begin{tabular}{|c|c|c|c|c|c|c|}
\hline \multirow{3}{*}{$\begin{array}{c}\text { Tem- } \\
\text { perature } \\
\theta\end{array}$} & \multicolumn{2}{|c|}{ Methyl alcohol } & \multicolumn{2}{|c|}{ Ethyl alcohol } & \multicolumn{2}{|c|}{ Benzene } \\
\hline & \multicolumn{2}{|c|}{$H]_{40}^{\theta}$} & \multicolumn{2}{|c|}{$I I]_{40}^{\theta}$} & \multicolumn{2}{|c|}{$I I]_{50}^{\theta}$} \\
\hline & Observed & Equation & Observed & Equation & Observed & Equation \\
\hline${ }^{\circ} \mathrm{C}$. & Int.J./g & Int. J./g & Int. J./ & Int. J./g & Int. $J . / O$ & Int. J./g \\
\hline $\begin{array}{l}50 \\
60 \\
70\end{array}$ & $\begin{array}{l}26.43 \\
53.73 \\
81.93\end{array}$ & $\begin{array}{l}26.47 \\
53.75 \\
81.91\end{array}$ & $\begin{array}{l}26.26 \\
53.51 \\
81.95\end{array}$ & $\begin{array}{l}26.26 \\
53.57 \\
81.99\end{array}$ & $\begin{array}{r}0.00 \\
18.50 \\
37.33\end{array}$ & $\begin{array}{r}0.00 \\
18.51 \\
37.32\end{array}$ \\
\hline $\begin{array}{r}80 \\
90 \\
100 \\
110\end{array}$ & $\begin{array}{l}111.04 \\
141.06 \\
172.24 \\
204.55\end{array}$ & $\begin{array}{l}111.01 \\
141.11 \\
172.26 \\
204.54\end{array}$ & $\begin{array}{l}111.62 \\
142.50 \\
174.92 \\
208.57\end{array}$ & $\begin{array}{l}111.62 \\
142.55 \\
174.86 \\
208.63\end{array}$ & $\begin{array}{r}56.43 \\
75.86 \\
95.63 \\
115.73\end{array}$ & $\begin{array}{r}56.43 \\
75.87 \\
95.63 \\
115.75\end{array}$ \\
\hline
\end{tabular}

For methyl alcohol

For ethyl alcohol

$$
H]_{\theta_{1}}^{\theta_{2}}=\left[23.529\left(\frac{\theta}{10}\right)+0.2583\left(\frac{\theta}{10}\right)^{2}+0.010036\left(\frac{\theta}{10}\right)^{\mathrm{g}}\right]_{\theta_{1}}^{\theta_{3}}
$$

For benzene

$$
H]_{\theta_{1}}^{\theta_{2}}=\left[22.648\left(\frac{\theta}{10}\right)+0.3053\left(\frac{\theta}{10}\right)^{2}+0.014233\left(\frac{\theta}{10}\right)^{3}\right]_{\theta_{1}}^{\theta_{3}}
$$

$$
H]_{\theta_{1}}^{\theta_{2}}=\left[17.184\left(\frac{\theta}{10}\right)+0.1008\left(\frac{\theta}{10}\right)^{2}+0.002462\left(\frac{\theta}{10}\right)^{3}\right]_{\theta_{1}}^{\theta_{2}}
$$

From the equations for $H]_{1}^{2}$ there were obtained values of a quantity $C_{\pi}=\frac{d H}{d \theta}$, defined as the rate of change of the heat content with temperature under saturation conditions. Since the values of $H]_{1}^{2}$ as recorded in Table 6 were measured under such conditions, equations for $C_{\pi}$ were obtained by differentiation of the equations already given for $H]_{1}^{2}$. The derived equations and the values of $C_{\pi}$ calculated at several temperatures are given in Table 8.

\begin{tabular}{|c|c|c|c|}
\hline \multirow{2}{*}{$\begin{array}{c}\text { Tempera- } \\
\operatorname{ture} \\
\theta\end{array}$} & $\begin{array}{l}\text { Methyl } \\
\text { alcohol }\end{array}$ & $\begin{array}{l}\text { Ethyl } \\
\text { alcohol }\end{array}$ & Benzene \\
\hline & $C \pi$ & $C \pi$ & $C \pi$ \\
\hline $\begin{array}{l}{ }^{\circ} C . \\
40 \\
50 \\
60 \\
70\end{array}$ & $\begin{array}{c}\text { Int. } J . / g .{ }^{\circ} \mathrm{C} \text {. } \\
\text { 2. } 608 \\
2.686 \\
\text { 2. } 771 \\
2.862\end{array}$ & $\begin{array}{c}\text { Int. } J . / g .{ }^{\circ} C . \\
\text { 2. } 577 \\
\text { 2. } 677 \\
\text { 2. } 785 \\
\text { 2. } 901\end{array}$ & $\begin{array}{c}\text { Int. } J . / g .{ }^{\circ} \mathrm{C} . \\
1.838 \\
1.866 \\
1.896\end{array}$ \\
\hline $\begin{array}{r}80 \\
30 \\
100 \\
110\end{array}$ & $\begin{array}{l}2.959 \\
\text { 3. } 062 \\
\text { 3. } 171 \\
\text { 3. } 286\end{array}$ & $\begin{array}{l}\text { 3. } 027 \\
\text { 3. } 160 \\
\text { 3. } 302 \\
3.453\end{array}$ & $\begin{array}{l}\text { 1. } 927 \\
1.960 \\
1.994 \\
2.030\end{array}$ \\
\hline
\end{tabular}

TABLE 8.-Computation of specific heat values

$$
C_{\pi}=\frac{d H}{d \theta}=C_{p} \text { (approsimately) }
$$

For methyl alcohol

$$
\mathrm{C} \pi=2.3529+0.5166\left(\frac{\theta}{10}\right)+0.003011\left(\frac{\theta}{10}\right)^{2}
$$

For ethyl alcohol

$$
C_{\pi}=2.2648+0.06106\left(\frac{\theta}{10}\right)+0.004270\left(\frac{\theta}{10}\right)^{2}
$$

For benzene

$$
C_{\pi}=1.7184+0.02016\left(\frac{\theta}{10}\right)+0.0007386\left(\frac{\theta}{10}\right)^{\prime}
$$


From specific volume and thermal expansion data it is possible to transform the values of changes in heat content under saturation conditions to values of the changes under a constant pressure of 1 atmosphere. Such transformations have been made and equations for $H]_{1}^{2}$ at $p=1$ atmosphere have been fitted.

From these it is possible to get derived equations for $C_{p}=\left(\frac{\partial H}{\partial \theta}\right)_{p=1 \mathrm{~atm}}$. defined as the rate of change of heat content with temperature under a constant pressure of 1 atmosphere. Values of $C_{p}$ were calculated for each of the three liquids at temperatures below the normal boiling points. A comparison of these values of $C_{p}$ with the recorded values of $C_{\pi}$ showed that the difference between the two was less than 1 part in 500 at every temperature. Since this difference is believed to be within the error involved in deriving values of specific heat from measured values of $\alpha$, the recorded values of $C_{\pi}$ are not sensibly different from the values of $C_{p}$ as indicated by these experiments.

The specific volumes of the saturated vapors can be calculated from the relation $\gamma=\theta u^{\prime} \frac{d \pi}{d \theta}$ to the degree of precision of our knowledge of $\frac{d \pi}{d \theta}$. The values of $u^{\prime}$ thus computed are shown in Table 9. The values of $\frac{d \pi}{d \theta}$ are calculated from Young's vapor pressure equations and the values of $\gamma$ result from the present investigation.

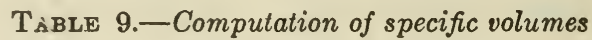

$$
u^{\prime}=\frac{\gamma}{\Theta \frac{d \pi}{d \theta}}
$$

\begin{tabular}{|c|c|c|c|c|c|c|c|c|c|c|}
\hline \multicolumn{2}{|c|}{ Temperature } & \multicolumn{3}{|c|}{ Methyl alchohol } & \multicolumn{3}{|c|}{ Ethyl alcohol } & \multicolumn{3}{|c|}{ Benzene } \\
\hline$\theta$ & $\theta$ & $\gamma$ & $\frac{d \pi}{d \Theta}$ & $u^{\prime}$ & $\gamma$ & $\frac{d \pi}{d \theta}$ & $u^{\prime}$ & $\gamma$ & $\frac{d \pi}{d \theta}$ & $u^{\prime}$ \\
\hline $\begin{array}{r}{ }^{\circ} \mathrm{C} . \\
0 \\
10 \\
20 \\
25 \\
30\end{array}$ & $\begin{array}{l}{ }^{\circ} K . \\
273.1 \\
283.1 \\
293.1 \\
298.1 \\
303.1\end{array}$ & $\begin{array}{r}\text { L.atm. } / g \\
11.85 \\
11.74 \\
11.61 \\
11.54 \\
11.47\end{array}$ & $\begin{array}{r}\text { Atm. } / \text { deg } \\
0.00245 \\
.00416 \\
.00677 \\
.00852 \\
.01061\end{array}$ & $\begin{array}{c}L . / g \\
17.71 \\
9.97 \\
5.851 \\
4.544 \\
3.567\end{array}$ & \begin{tabular}{|r|} 
L. -atm. $/ g$ \\
9.340 \\
9.243 \\
9.137 \\
9.081 \\
9.020
\end{tabular} & $\begin{array}{c}\text { Atm./deg } \\
0.00111 \\
.00200 \\
.00344 \\
.00443 \\
.00570\end{array}$ & $\begin{array}{c}L . / g \\
30.81 \\
16.32 \\
9.062 \\
6.877 \\
5.221\end{array}$ & $\begin{array}{r}\text { L. -atm./g } \\
4.416 \\
4.356 \\
4.298 \\
4.266 \\
4.235\end{array}$ & $\begin{array}{c}\text { Atm./deg. } \\
(0.0020) \\
.00309 \\
.00469 \\
.00586 \\
.00688\end{array}$ & $\begin{array}{r}L . / g \\
8.085 \\
4.980 \\
3.127 \\
2.442 \\
2.031\end{array}$ \\
\hline $\begin{array}{l}40 \\
50 \\
60 \\
70 \\
80\end{array}$ & \begin{tabular}{l|l|}
313.1 \\
323.1 \\
333.1 \\
343.1 \\
333.1
\end{tabular} & $\begin{array}{l}11.31 \\
11.14 \\
10.97 \\
10.78 \\
10.58\end{array}$ & $\begin{array}{l}.01606 \\
.02353 \\
.03355 \\
.01651 \\
.06302\end{array}$ & $\begin{array}{l}2.249 \\
1.465 \\
.9816 \\
.6755 \\
.4755\end{array}$ & $\begin{array}{l}8.894 \\
8.757 \\
8.611 \\
8.454 \\
8.287\end{array}$ & $\begin{array}{l}.00907 \\
.01394 \\
.02073 \\
.02989 \\
.04192\end{array}$ & $\begin{array}{l}3.132 \\
1.944 \\
1.247 \\
.8244 \\
.5599\end{array}$ & $\begin{array}{l}4.171 \\
4.106 \\
4.039 \\
3.971 \\
3.902\end{array}$ & $\begin{array}{l}.00978 \\
.01350 \\
.01814 \\
.02383 \\
.03064\end{array}$ & $\begin{array}{l}1.362 \\
.9413 \\
.6684 \\
.4857 \\
.3607\end{array}$ \\
\hline $\begin{array}{r}90 \\
100 \\
110 \\
120 \\
130\end{array}$ & $\begin{array}{l}363.1 \\
373.1 \\
383.1 \\
303.1 \\
403.1\end{array}$ & $\begin{array}{r}10.36 \\
10.13 \\
9.89 \\
9.64 \\
9.37\end{array}$ & $\begin{array}{l}.08359 \\
.1088 \\
.1391 \\
.1751 \\
.2174\end{array}$ & $\begin{array}{r}.3413 \\
.2495 \\
.1856 \\
.1401 \\
.1089\end{array}$ & $\begin{array}{l}8.110 \\
7.922 \\
7.727 \\
7.517 \\
7.299\end{array}$ & $\begin{array}{l}.05729 \\
.07648 \\
.0999 \\
.1280 \\
.1612\end{array}$ & $\begin{array}{l}.3899 \\
.2778 \\
.2019 \\
.1494 \\
.1123\end{array}$ & $\begin{array}{l}3.831 \\
3.759 \\
3.684 \\
3.605 \\
3.542\end{array}$ & $\begin{array}{l}.03865 \\
.04794 \\
.05857 \\
.07059 \\
.08407\end{array}$ & $\begin{array}{l}.2730 \\
.2102 \\
.1642 \\
.1300 \\
.1045\end{array}$ \\
\hline
\end{tabular}

Table 10 has been prepared to summarize the thermal properties of these three saturated fluids. The values of $\pi$ are from the data of Young. The values of $u$ at temperatures below the normal boiling points are from density determinations as recorded in the International Critioal Tables, volume 3, pages 27 to 30 . Values of $u$ above the boiling points are those determined by Young. The values of $u^{\prime}$ are computed as shown in Table 9. The results of the present 
investigation are extrapolated down to $0^{\circ} \mathrm{C}$. and up to $130^{\circ} \mathrm{C}$. The value of $\mathrm{H}$ has been arbitrarily chosen as $0^{\circ}$ at $0^{\circ} \mathrm{C}$. for each liquid. For the benzene which freezes at about $5^{\circ}$ above this temperature the datum $H=0$ is for the undercooled liquid. The heat of fusion is therefore not included in the tabulated values.

It is hoped that this table may prove useful as a working table for those who are concerned with the thermal properties of any one of these saturated fluids.

TABLE 10. - Thermal properties of methyl alcohol, ethyl alcohol, and benzene at saturation

METHYL ALCOHOL

\begin{tabular}{|c|c|c|c|c|c|c|}
\hline \multirow{2}{*}{$\begin{array}{l}\text { Temper- } \\
\text { ature } \theta\end{array}$} & \multirow{2}{*}{$\begin{array}{l}\text { Vapor pres- } \\
\text { sure } \pi\end{array}$} & \multicolumn{2}{|c|}{ Specific rolume } & \multirow{2}{*}{$\begin{array}{c}\text { Heat con- } \\
\text { tent Liquid } \\
H\end{array}$} & \multirow{2}{*}{$\underset{I}{\text { Latent heat }}$} & \multirow{2}{*}{$\begin{array}{c}\text { Heat con- } \\
\text { tent Va- } \\
\text { por } H^{\prime}\end{array}$} \\
\hline & & $\begin{array}{l}\text { Liquid } \\
u \times 10^{3}\end{array}$ & Vapor $u^{\prime}$ & & & \\
\hline $\begin{array}{r}{ }^{\circ} C . \\
0 \\
10 \\
20 \\
25 \\
30\end{array}$ & $\begin{array}{c}\text { Atmospheres } \\
0.0389 \\
.0713 \\
.1251 \\
.1632 \\
.2109\end{array}$ & $\begin{array}{r}\text { Liter } / / g \\
1.234 \\
1.249 \\
1.264 \\
1.271 \\
1.279\end{array}$ & $\begin{array}{c}\text { Liters/g } \\
17.71 \\
9.97 \\
5.851 \\
4.544 \\
3.567\end{array}$ & $\begin{array}{c}\text { Int. } J . / g \\
0.0 \\
23.80 \\
48.17 \\
60.59 \\
73.18\end{array}$ & $\begin{array}{r}\text { Int. J./g } \\
1,200.1 \\
1,188.5 \\
1,175.4 \\
1,168.4 \\
1,161.0\end{array}$ & $\begin{array}{r}\text { Int. J./g } \\
1,200.1 \\
1,212.3 \\
1,223.6 \\
1,229.0 \\
1,234.2\end{array}$ \\
\hline $\begin{array}{l}40 \\
50 \\
60 \\
70 \\
80\end{array}$ & $\begin{array}{l}.3427 \\
.5388 \\
.8255 \\
1.219 \\
1.764\end{array}$ & $\begin{array}{l}1.295 \\
1.311 \\
1.324 \\
1.340 \\
1.360\end{array}$ & $\begin{array}{l}2.249 \\
1.465 \\
.9816 \\
.6755 \\
.4755\end{array}$ & $\begin{array}{l}98.89 \\
125.4 \\
152.6 \\
180.8 \\
209.9\end{array}$ & $\begin{array}{l}1,145.3 \\
1,128.2 \\
1,109.7 \\
1,089.3 \\
1,068.3\end{array}$ & $\begin{array}{l}1,244.2 \\
1,253.6 \\
1,262.3 \\
1,270.6 \\
1,278.2\end{array}$ \\
\hline $\begin{array}{r}90 \\
100 \\
110 \\
120 \\
130\end{array}$ & $\begin{array}{l}2.493 \\
3.451 \\
4.686 \\
6.252 \\
8.209\end{array}$ & $\begin{array}{l}1.379 \\
1.401 \\
1.424 \\
1.449 \\
1.477\end{array}$ & $\begin{array}{l}.3413 \\
.2495 \\
.1858 \\
.1401 \\
.1069\end{array}$ & $\begin{array}{l}240.0 \\
271.2 \\
303.4 \\
336.9 \\
371.6\end{array}$ & $\begin{array}{r}1,045.2 \\
1,020.5 \\
994.1 \\
965.9 \\
935.7\end{array}$ & $\begin{array}{l}1,285.2 \\
1,291.7 \\
1,297.5 \\
1,302.8 \\
1,307.3\end{array}$ \\
\hline
\end{tabular}

ETHYL ALCOHOL

\begin{tabular}{|r|r|r|r|r|r|r|}
\hline 0 & 0.0162 & 1.240 & 30.81 & 0.0 & 946.0 & 946.0 \\
10 & .0312 & 1.253 & 16.32 & 22.97 & 936.2 & 959.2 \\
20 & .0579 & 1.267 & 9.062 & 46.63 & 925.4 & 972.0 \\
25 & .0771 & 1.274 & 6.877 & 58.75 & 919.6 & 978.4 \\
30 & .1028 & 1.281 & 5.221 & 71.08 & 913.5 & 984.6 \\
40 & .1756 & 1.295 & 3.132 & 96.39 & 900.5 & 996.9 \\
50 & .2892 & 1.310 & 1.944 & 122.7 & 886.5 & $1,009.2$ \\
60 & .4608 & 1.326 & 1.247 & 150.0 & 871.3 & $1,021.3$ \\
70 & .7117 & 1.343 & .8244 & 178.4 & 854.9 & $1,033.3$ \\
80 & 1.068 & 1.361 & .5599 & 208.0 & 837.3 & $1,045.3$ \\
90 & 1.561 & 1.379 & .3899 & 239.9 & 818.5 & $1,058.4$ \\
100 & 2.227 & 1.397 & .2776 & 271.2 & 798.4 & $1,069.6$ \\
110 & 3.105 & 1.417 & .2019 & 305.0 & 777.0 & $1,082.0$ \\
120 & 4.241 & 1.444 & .1494 & 340.3 & 754.0 & $1,094.3$ \\
130 & 5.682 & 1.473 & .1123 & 377.3 & 729.6 & $1,106.9$ \\
\hline
\end{tabular}

BENZENE

\begin{tabular}{|r|r|r|r|r|r|r|}
\hline 0 & 0.0349 & 1.111 & 8.805 & 0.0 & 447.2 & 447.2 \\
10 & .0598 & 1.124 & 4.980 & 17.29 & 441.2 & 458.5 \\
20 & .0982 & 1.138 & 3.127 & 34.79 & 435.0 & 469.8 \\
25 & .1235 & 1.145 & 2.442 & 43.59 & 431.9 & 475.5 \\
30 & .1556 & 1.152 & 2.031 & 52.52 & 428.7 & 481.2 \\
40 & .2383 & 1.168 & 1.262 & 70.51 & 422.1 & 492.6 \\
50 & .3539 & 1.181 & .9413 & 88.75 & 415.4 & 504.2 \\
60 & .5113 & 1.197 & .6684 & 107.3 & 408.4 & 508.6 \\
70 & .7203 & 1.213 & .4857 & 126.1 & 401.3 & 527.4 \\
80 & .9916 & 1.228 & .3607 & 145.2 & 393.9 & 539.1 \\
90 & 1.337 & 1.244 & .2730 & 164.6 & 386.3 & 550.9 \\
100 & 1.769 & 1.262 & .2102 & 184.4 & 378.4 & 562.8 \\
110 & 2.300 & 1.281 & .1642 & 204.5 & 370.3 & 574.8 \\
120 & 2.945 & 1.300 & .1300 & 225.0 & 361.9 & 586.9 \\
130 & 3.717 & 1.321 & .1045 & 245.8 & 353.2 & 899.0 \\
\hline
\end{tabular}




\section{DISCUSSION OF ACCURACY}

An estimate of the accuracy of the tabulated values of $H$ and $L$ within the range of the experiments has been made on a basis similar to that outlined in the report on the properties of steam. The systematic errors in calorimetry are believed to be essentially the same in both sets of experiments.

By a study of the factors which enter into the measurements, a figure was assigned to each which represents an estimate of the outstanding systematic error, after all known corrections have been applied. In addition to these, corresponding figures were deduced which represent the error in both the $\alpha$ and the $\gamma$ due to accidental errors in the measurements. An estimate was also made of the probable error in the calculated values of $\beta$. The density determinations furnish a basis for estimating the error which may be present on account of impurities in the liquids investigated.

These estimates were combined to obtain a value for the uncertainty in the final tabulated results. On this basis it is believed that more precise determinations on compounds of a higher degree of purity would yield values of $H$ and $L$ differing by less than 1 part per 1,000 from those of the present investigation in the range from $40^{\circ}$ to $110^{\circ} \mathrm{C}$.

\section{COMPARISON WITH PREVIOUS WORK}

\section{HEAT CAPACITY}

The results of calorimetric determinations of heat capacity have usually been recorded in terms of specific heats. For comparison of the present results with those of other observers the calculated values of specific heats can be compared directly, or, where equations are available, the values of changes in heat content can be calculated from integrated specific heat equations. The latter method would have been followed if the termperature ranges of the various experiments had overlapped sufficiently. However, the earlier work is confined to the range well below the normal boiling points, and hence covers regions in general, below that of the present investigation.

The values of specific heat indicated by the present work have been extrapolated down to $20^{\circ} \mathrm{C}$. for purposes of comparison. The extrapolated values of this derived quantity involve considerable uncertainties and should not be given a great deal of weight in the selection of the best values below $40^{\circ} \mathrm{C}$. A graphical comparison of previously published values of specific heats with those of the present work is given in Figure 2. This summary includes the experimental results of Bose, ${ }^{8}$ Kelley, ${ }^{9}$ Williams, and Daniels, ${ }^{10}$ Forch, ${ }^{11}$ Mills and MacRae, ${ }^{12}$ Dejardin, ${ }^{13}$ Tréhin, ${ }^{14}$ and Andrews, Lynn, and Johnston. ${ }^{15}$

\footnotetext{
8 Z. phys. Chem., 58, p. 585; 1907.

J. Am. Chem. Soc., 51, p. 180; 1929; and 51, p. 779; 1929

10 J. Am. Chem. Soc., 46, p. $903 ; 1024$.

11 Annalen der Physik, 317, p. 202; 1903.

12 J. phys. Chem., 14, p. 797; 1910.

13 Annales de Physique, 11, p. 253; 1919.

14 Annales de Physique, 15, p. 246; 1921.

is J. Am. Chom. Soc., is, p. 1274; 1926.
} 

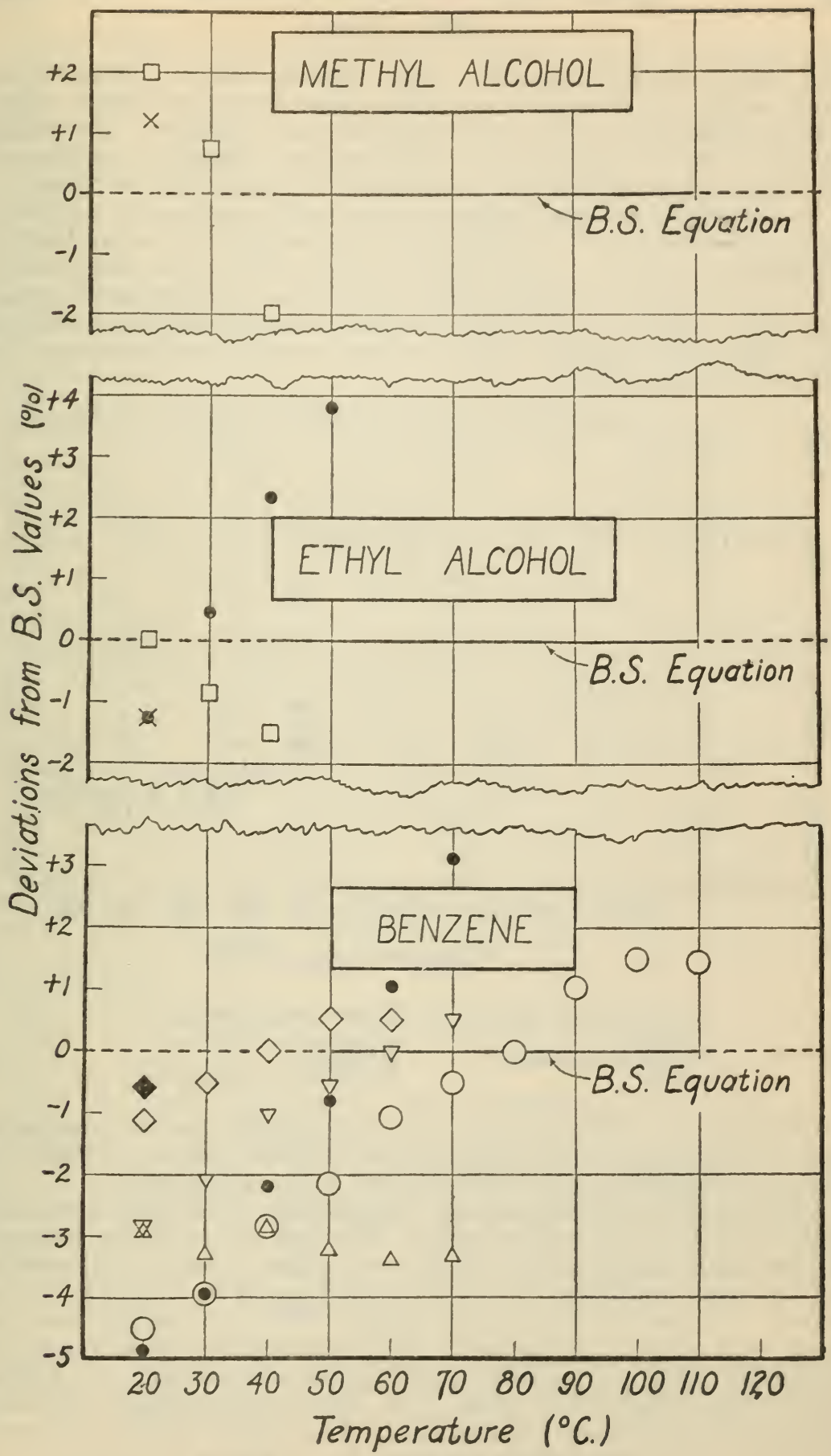

Figure 2.--Comparison of specific heats 


\section{LATENT HEAT}

In the following comparison of the various values of latent heats which appear in the literature, those data based on direct calorimetric measurements will be given first consideration. The values which have been calculated from other types of measurements through the Clapeyron relation are not considered of comparable precision.

An attempt has been made to reduce the previously published values of latent heats to present international joules for purposes of comparison. Such a reduction involves considerable uncertainty, but this is believed to be within the limit of error involved in the measurements themselves. It is not possible to make reliable estimates of the purity of the liquids used by various investigators because of the lack of published details.

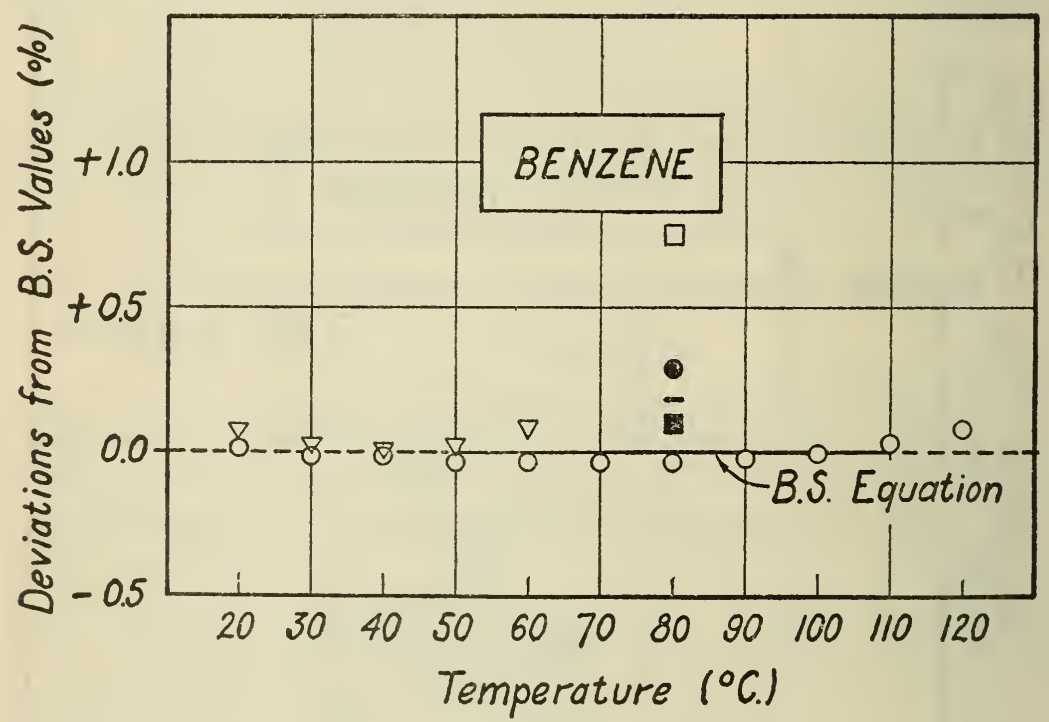

Figure 3.-Comparison of latent heats of benzene

$\square$ Brown.

$\nabla$ Griffiths and Marshall. - Tyrer.
Nagornow and Rotinjanz.

S Mathews.

The data on methyl alcohol and ethyl alcohol are too meager to warrant exhibition on deviation charts. Figure 3 gives a comparison of the experimental values of the latent heat of benzene.

The literature records two determinations of the latent heat of methyl alcohol at its boiling point. The first of these is by Brown ${ }^{16}$ and the second by Mathews. ${ }^{17}$ Brown's value is reported in calories and has been multiplied by 4.199 and decreased by 1 part in 512 to convert to present international joules. When so transiormed, his value for $L$ at $64.7^{\circ} \mathrm{C}$. becomes $1,101.6$ international joules per gram. Mathews' value for $L$ at the same temperature reduces to $1,100.5$ international joules per gram. The latter is identical with that indicated by the present experiments. For methyl alcohol the agreement among the few results is satisfactory. 
Three values for the latent heat of ethyl alcohol at its boiling point are recorded. Marshall and Ramsay ${ }^{18}$ determined the ratio of the latent heat of absolute ethyl alcohol at its boiling point to that of benzene at the same temperature. This ratio, 2.293, together with the value of Griffiths and Marshall for the latter, indicates a latent heat for the alcohol of 902.7 international joules per gram at $80^{\circ} \mathrm{C}$.

A determination by Brown, ${ }^{19}$ when transformed as alreadv described gives a value of $L$ for ethyl alcohol at $80^{\circ} \mathrm{C}$. of 903.5 international joules per gram. The work of Mathews ${ }^{20}$ gives the value 840.3 international joules per gram for $L$ at the same temperature. The density which he records for his sample indicates that it may have contained mearly 0.2 per cent of water. The comparative value indicated by the present experiments is 837.3 international joules per gram. The alcohol samples which gave values of the latent heat of over 900 joules per gram were probably not dry. The agreement with the value of Mathews is moderately good, the difference probably being largely due to the small amount of water in his sample.

Considerable data are available on the heat of vaporization of benzene. These will be discussed in chronological order.

The work of Griffiths and Marshall ${ }^{21}$ at temperatures from $20^{\circ}$ to $50^{\circ}$ C. gave values which were represented by the equation $L=$ $107.05-0.158 \theta$, in terms of a calorie defined as 4.199 joules. To convert to present international joules, the coefficients of the righthand member have been multiplied by 4.199 and decreased by 1 part in 512, because of the changes in electrical units since the work was performed. The transformed equation which gives values of $L$ in international joules is $L=448.6-0.66 \theta$.

The work of Tyrer ${ }^{22}$ gives a value of the latent heat of benzene at its boiling point in terms of a calorie based on indications of a voltmeter and silver voltameter. From the date of this work it is assumed that the units were those established by international agreement in 1910. On this basis the electrical equivalent of the calorie used by Tyrer becomes 4.188 international joules. His value for the latent heat of benzene at $80^{\circ} \mathrm{C}$. then becomes 394.8 international joules per gram.

Nagornow and Rotinjanz ${ }^{23}$ report a group of determinations which yielded a mean value of 393.4 international joules per gram as the latent heat of benzene at $80^{\circ} \mathrm{C}$.

From the work of Mathews ${ }^{24}$ the value 395.1 international joules per gram at $80^{\circ} \mathrm{C}$. is indicated.

Sutcliffe, Lay and Prichard ${ }^{25}$ determined the latent heat of benzene from its boiling point up to $152^{\circ} \mathrm{C}$, and by combining their data with those of Griffiths and Marshall, fitted an equation to the experimental values in the range $20^{\circ}$ to $150^{\circ} \mathrm{C}$. Transformed to yield values of $L$ in international joules per gram, this equation becomes

$$
L=447.72-0.6163 \theta-6.141 \times 10^{-4} \theta^{2}-1.509 \times 10^{-6} \theta^{3}
$$

The agreement among the values of $L$ for benzene in the entire range is very gratifying. The equation of Sutcliffe, Lay, and Prichard, which represents the data of Griffiths and Marshall as well as

15 Phil. Mag., 41, p. 38; 1896.

19 J. Chem. Soc., 87, p. 265; 1905.

20 See footnote 17, p. 898.

21 Phil. Mag. 41, p. 1; 1896.
22 J. Chem. Soc., 99, p. 1633; 1911.

23 Z. phys. Chem., 77, p. 700; 1911 .

24 See footnote 17, p. 898 .

is Proc. Roy. Soc. London, 115, p. 88; 1927. 
their own, yields values which are everywhere in agreement with those calculated from our equation, within the limit of our own experimental error.

For all three of the fluids the values of $L$ derived from the present measurements differ from those caluclated from the data of Young with the aid of the Clapeyron relation by approximately 1 part in 50 at the boiling points and 1 part in 100 at $110^{\circ} \mathrm{C}$.

\section{SUMMARY}

Thermal properties of methyl alcohol, ethyl alcohol, and benzene were investigated in the temperature range $40^{\circ}$ to $110^{\circ} \mathrm{C}$. Determinations were made of the latent heats of vaporization and the changes in heat content of the saturated fluids in this range. The results have been assembled in the form of tables and empirical equations have been fitted to the experimental values to aid in the application of the data. A working table of the thermal properties of these three fluids at saturation conditions has been prepared from the present and previously published data.

\section{ACKNOWLEDGMENT}

The authors wish to extend their thanks to N. S. Osborne and H. F. Stimson, of this laboratory, as well as to all others who have aided in the project.

Washington, March 10, 1931. 